\title{
Controlling Effect of Fault Structural Styles on Aquifer Water Abundance for Panxie Mining Area, Huainan, China
}

\author{
Jingying Li, Qimeng Liu, Huichan Chai, Zhigang Xie \\ College of Earth and Environment, Anhui University of Science and Technology, Huainan, China \\ Email:1691150139@qq.com
}

How to cite this paper: Li, J.Y., Liu, Q.M., Chai, H.C. and Xie, Z.G. (2019) Controlling Effect of Fault Structural Styles on Aquifer Water Abundance for Panxie Mining Area, Huainan, China. Open Journal of Safety Science and Technology, 9, 145-156. https://doi.org/10.4236/ojsst.2019.94010

Received: October 15, 2019

Accepted: November 15, 2019

Published: November 18, 2019

Copyright () 2019 by author(s) and Scientific Research Publishing Inc. This work is licensed under the Creative Commons Attribution International License (CC BY 4.0).

http://creativecommons.org/licenses/by/4.0/

\begin{abstract}
According to the hydrogeological conditions, dynamic characteristics of tectonic deformation and geometric features, the fault structures in the Panxie mining area were divided into seven types respectively were horst, graben, graben-horst combination, forward (reverse) thrust structure, imbricate thrust structure, strike-slip structure, and others. Meanwhile, the $q$-structural styles boxplot had been constructed to analyze the water abundance of the karst formation aquifer. It has been verified via the practical drilling core data. The final results were that the water-rich characteristics of the deep karst water controlled by the seven structural styles were different. The water abundance of graben-horst combination structure was strongest; the next was the horst in deep which was stronger than the graben. Then, the imbricate thrust structure, strike-slip fault, and other structural styles had low water abundance in deep karst aquifer. The results can be aimed at different structural styles to guide the prevention and control of karst water hazards on the floor of Group A coal mining.
\end{abstract}

\section{Keywords}

Water Abundance, Fault Structural Styles, Taiyuan Formation Limestone, Box Plot, Water Hazard Control

\section{Introduction}

The crustal structure style has always been a research hotspot of geosciences, which is of great significance to exploring the evolution mechanism of exploration plate movement and the global geology framework [1] [2] [3]. In addition, the exploration of structural styles plays an irreplaceable role in revealing the 
history of geological tectonic evolution, geodynamic evolution mechanism, and topographical features [4] [5] [6], especially in oil and gas control, coal control mode, mineral resources exploration and evaluation; it has played a substantial role [7] [8] [9] [10] [11]. Therefore, the study of structural style has both profound geological significance and practical scientific application value [12] [13].

In recent years, with the increase of coal mining depth and the expansion of scale, the water pressure of karst water in the floor is increasing continuously, especially in complex areas with fault structures, and the occurrence of water inrush accidents is more likely [14] [15] [16]. In the past, most of the researches on structural water control only considered the water conductivity of a certain fault, which could not reflect the general characteristics of the structural combination and the water control law, and the structural style was rarely used in the water control field. More so, for enriching study results, seeking new ideas and new methods of structural water control, so the paper started from the fault structure styles, taking stratigraphic characteristics, holistic form of fault structure, fault property, and many other factors into consideration, there is more emphasis on the control functions of tectonic styles on water abundance. The Panxie mining area in Huainan coalfield was selected as the study area. According to its the hydrogeological conditions, fracture classification and division of structural units, fracture profile morphology and stress mechanism, the fault combination structure in the area was divided into seven styles, and then the unit water inflow-structural style box plot was used to analyze the water richness of Taiyuan formation aquifer. Also the research results could be verified through the leakage condition reflected by pumping borehole. This study combines quantitative analysis with qualitative analysis, also applies theory to practice, which creates new ideas and methods for exploring the law of water control in deep, and provides a theoretical basis for the prevention and control of karst water damage in coal mines.

\section{Study Area}

\subsection{Overview}

Huainan Coalfield is located in the north-central part of Anhui Province, China, which spans both sides of the Huainan River, and mainly in Huainan City. From the plane view, Huainan Coalfield is long and ellipsoid shaped in the NWW direction. Panxie Mining Area is situated in the central part of Huainan Coalfield, with a total area of $1571 \mathrm{~km}^{2}$. Because it is located in the Huaihe River alluvial plain, its terrain is relatively flat, while it presents the overall layout of high in the northwest and low in the southeast. The surface rivers are vertical and horizontal, and the water system belongs to the Huaihe River Basin. The main coal bearing strata are Permian Shanxi formation, Lower Shihezi Formation, and upper Shihezi Formation, which consist of seven coal-bearing members and a no-coal segment, the total thickness of the coal bearing zone is $750 \mathrm{~m}$. The aquifer (formation) in this area is composed of Cenozoic unconsolidated layers pore 
water, Triassic sandstone fracture water, Permian sandstone fissure water, and Carboniferous Taiyuan limestone karst fissure water. The development of folds and faults in the area provides a good channel for groundwater runoff, which makes the hydraulic connections among aquifers. According to the existing hydrogeological survey data, the overall hydrogeological type of mining area is medium to complex.

\subsection{Limestone of Taiyuan Formation}

The limestone of Taiyuan Formation in Panxie Mining Area is a direct water-filled aquifer of coal Group A, which has a great influence on the coal mining of Group A, so exploration of the law of water-rich aquifer in the karst aquifer is vital. The Taiyuan Formation consists of limestone, mudstone, sandy mudstone, and medium-fine sandstone, which reflects the sedimentary characteristics of the Late Carboniferous-Early Permian sea-continental facies. The limestone contains 11 - 13 layers with a thickness of $53.53 \mathrm{~m}$, accounting for about $44.3 \%$ of the total thickness; it has water-bearing conditions in Taiyuan formation aquifer. Among them, the upper and lower limestone is stable in the whole region, their thickness is large, and the rest are thin layer limestone. According to its thickness and karst development, the Taiyuan Formation limestone can be divided into three groups from top to bottom, namely the C3I group, C3II group and C3III group, each group containing 3 - 6 layers of limestone. Table 1 is a summary of the Carboniferous strata.

\section{Materials and Methods}

\subsection{Statistical Classification of Fault Structural Styles}

The fractured structure controls the occurrence characteristics of deep karst water, and the statistical classification of fracture structure style is the basis for exploring the structural style to the law of deep karst water control. Only by dividing the types of structural styles can we elude the differences among different types of structural styles on controlling water regularities. Therefore, according to hydrogeological conditions, structural deformation dynamics and geometrical features in the study area, the classification of structural styles of all fracture structures in eleven mines would be done.

Table 1. Carboniferous formation simple table.

\begin{tabular}{|c|c|c|}
\hline $\begin{array}{c}\text { Formation } \\
\text { Name }\end{array}$ & Thickness/(m) & Lithology \\
\hline $\begin{array}{c}\text { Taiyuan } \\
\text { Formation }\end{array}$ & $88-160$ & $\begin{array}{l}\text { limestone, dark gray (containing) bioclastic limestone } \\
\text { and dark gray silty mudstone interbedded with thin } \\
\text { carbonaceous mudstone and coal }\end{array}$ \\
\hline $\begin{array}{c}\text { Benxi } \\
\text { Formation }\end{array}$ & $1-30$ & $\begin{array}{l}\text { the bottom of Benxi Formation is dark purple-red } \\
\text { conglomerate-bearing iron mudstone with green } \\
\text { aluminous mudstone, purple-grey silty mudstone } \\
\text { and light flesh red microcrystalline limestone }\end{array}$ \\
\hline
\end{tabular}




\subsection{Data Analysis Method}

The data of unit water inflow collected in Table 2 are scattered and not intuitive, and it is difficult to find rules for analysis. Therefore, the visually intuitive box plot is chosen as the tool of data analysis. The effective information provided in the box diagram is maximum, median, mean and minimum.

\subsection{Validation}

Based on the data of 65 boreholes in the Taiyuan Formation limestone stratum and 813 borehole core samples in the study area, the water abundance of various structural styles was further confirmed. It was found that 6 boreholes in the graben-horst structure have leaked water, the rate of leaking water is $20.5 \%$, accounting for $62 \%$ of the total number of leaking water holes in the whole area, accompanied by the phenomenon of drilling loss and core uncovering. It is suspected that subsidence columns are developed in some places with large water output. Secondly, the drilling holes in horst and graben structures also had water leakage phenomena to varying degrees, water abundance was medium. The drilled holes in the thrust structure and the shingling thrust structure did not leak. Only one borehole in the strike-slip fault structural development section had a water leakage phenomenon, and the water leakage was very small, so water richness was weak. Drilling data in other fracture styles showed occasional leakage. It can be seen that the results obtained from the box plot were consistent with the actual situation, that is, the structural style had a certain control effect on the water-rich water layer of the Taiyuan Formation limestone aquifer in the study area, as well as the initial deep karst water-rich can be preliminarily judged through analyzing the type of structural styles. Figure 1 is an image of the limestone cores of different structural styles in the study area. It can be seen that there are obvious differences between water storage space and different structural styles.

\section{Results}

\subsection{Classification of Structure Styles}

The result is that there are mainly six types and other fault structure combination patterns in the study area. The following is a detailed description of each type of fault structure pattern.

\section{1) Graben}

According to the different combination styles and geometric shapes, the graben fault assemblages in the Panxie mining area can be divided into two categories, namely graben type, and semi-graben type.

\section{a) Graben type}

There are many types of grabens in the area, but a small scale. They are mostly composed of three-level faults, such as the graben is comprised of F92-1, F93 and FS298 faults on exploration line 10 of Gubei Mine. 
Table 2. Unit-inflow data of each structure style.

\begin{tabular}{|c|c|c|}
\hline Structural styles & Drill name & $q /\left(\mathrm{L} \cdot \mathrm{s} \cdot \mathrm{m}^{-1}\right)$ \\
\hline \multirow{7}{*}{ Graben } & S7 & 0.306 \\
\hline & $\mathrm{SN}$ & 0.00229 \\
\hline & SY-SE & 0.093 \\
\hline & XWC3-I & 0.0865 \\
\hline & XWC3II-1 & 0.003 \\
\hline & BIXLZ1 & 0.201 \\
\hline & BIXLZ2 & 0.054 \\
\hline \multirow{7}{*}{ Horst } & SY & 0.00487 \\
\hline & SS21 & 0.00141 \\
\hline & S52 & 0.251 \\
\hline & XIVW2 & 0.0915 \\
\hline & S3 & 0.518 \\
\hline & S8 & 0.00275 \\
\hline & S29 & 0.0342 \\
\hline \multirow{7}{*}{ Graben-horst combination style } & SSKz1 & 0.508 \\
\hline & XLZ5 & 0.05 \\
\hline & XLZ3 & 0.07 \\
\hline & XLZ2 & 0.06 \\
\hline & XLZ1 & 0.0985 \\
\hline & S217 & 0.57 \\
\hline & S210 & 0.296 \\
\hline \multirow{7}{*}{ Forward (reverse) thrust } & FJ & 0.00168 \\
\hline & SC3I-1 & 0.00323 \\
\hline & SC3I-2 & 0.000323 \\
\hline & SC3-II & 0.00017 \\
\hline & WF3 & 0.00292 \\
\hline & BK213 & 0.0006 \\
\hline & EL13 & 0.0000055 \\
\hline \multirow{7}{*}{ Imbricate thrust structure } & VIWC3-I & 0.007 \\
\hline & VIWC3-II & 0.0013 \\
\hline & VIWC3-III & 0.00059 \\
\hline & VIW02 & 0.0055 \\
\hline & $\mathrm{BKz} 1$ & 0.00015 \\
\hline & BVKz1 & 0.00023 \\
\hline & EJ5 & 0.00197 \\
\hline \multirow{7}{*}{$\begin{array}{l}\text { Translational faults and striking } \\
\text { sliding structures }\end{array}$} & XLZE1 & 0.135 \\
\hline & XLZE1 & 0.126 \\
\hline & XLZE1 & 0.0099 \\
\hline & XLZE1 & 0.0073 \\
\hline & XLZE2 & 0.000674 \\
\hline & XLZE2 & 0.00126 \\
\hline & SWC3I-1 & 0.00056 \\
\hline \multirow{7}{*}{ Other structural styles } & WF2 & 0.00435 \\
\hline & G8 & 0.0187 \\
\hline & S39 & 0.0176 \\
\hline & 848 & 0.0178 \\
\hline & WF3 & 0.0233 \\
\hline & EB5 & 0.002 \\
\hline & EE12 & 0.00578 \\
\hline
\end{tabular}




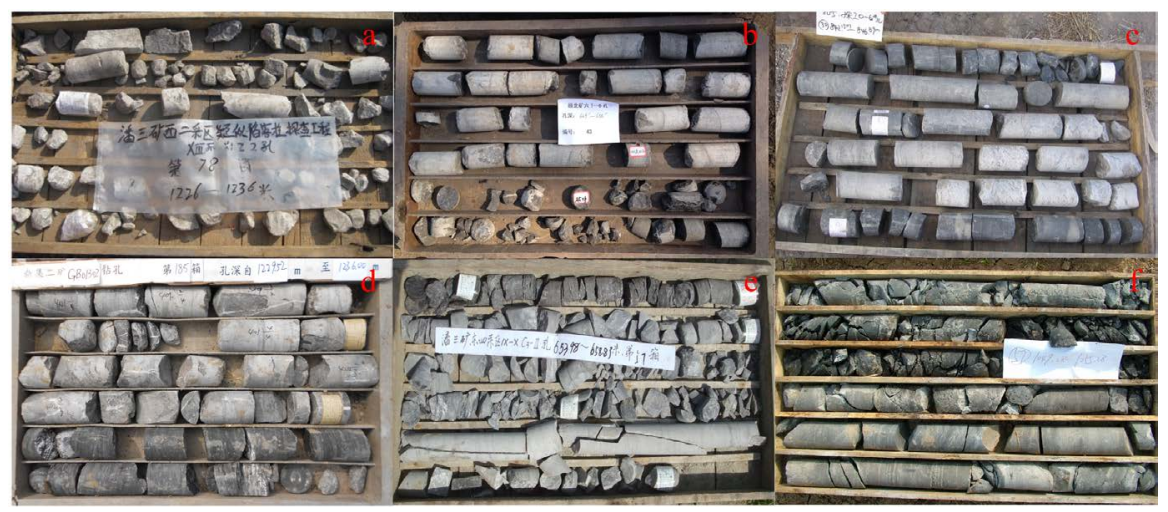

Figure 1. Taiyuan group limestone core graphs. (a) graben-horst combination structure; (b) horst; (c) graben; (d) strike-slip fault; (e) imbricate thrust structure; (f) other structure.

\section{b) Semi-graben}

The distribution of semi-graben structures in the Panxie mining area is not very wide. It only distributes in a few mines with a small scale and drop (Figure 2). Most of them had formed in short-term sedimentary structure and controlled by boundary and main faults. Besides, semi-graben structure is easy to form unilateral sedimentary overlap or form small fault basins and usually associated by several synclinal faults, these are generally products of the same tectonic period.

\section{2) Base}

Unlike grabens, there are relatively few types of horst in the Panxie mining area, and the controlling faults of horsts are generally non-rotating. In the study area, Pansidong Mine has more horst structures (Figure 3), generally, there are also a series of secondary faults inside the horst structure. Besides, small horsts in minefields are also more common. The horst formation area is the bedrock uplift area, and the coal measures strata are relatively shallow. Therefore, although the number of structural styles of the horst in Huainan coalfield is limited and the scale is small, the longitudinal profile depth of most horsts can reach the limestone layer of Taiyuan Formation below Group A coal, then affect the water-rich of aquifers.

\section{3) Graben-horst Combination Style}

Usually, grabens and horsts develop together in fault basins formed by tension stress, so the structural style of graben-horst combination is also the main structural form of Huainan coalfield, especially, the three mining areas of Xieqiao, Zhangji, and Gubei in the central part are the most prominent. Generally speaking, in the graben area, Paleogene stratification is more common and coal measures strata host deeper; in the horst area, bedrock outcrop is sporadically exposed, coal measures strata are shallow or denuded.

\section{4) Forward (Reverse) Thrust}

In areas with strong tectonic activity, thrust faults are often formed, for example, reverse thrust or thrust faults may occur near single thrust faults. In the southern part of Panbei minefield, complex thrust faults intersect had been given strong thrust action of tectonic movement, forming two sets of reverse thrust structures in East and west directions and interlacing with each other (Figure 4). 


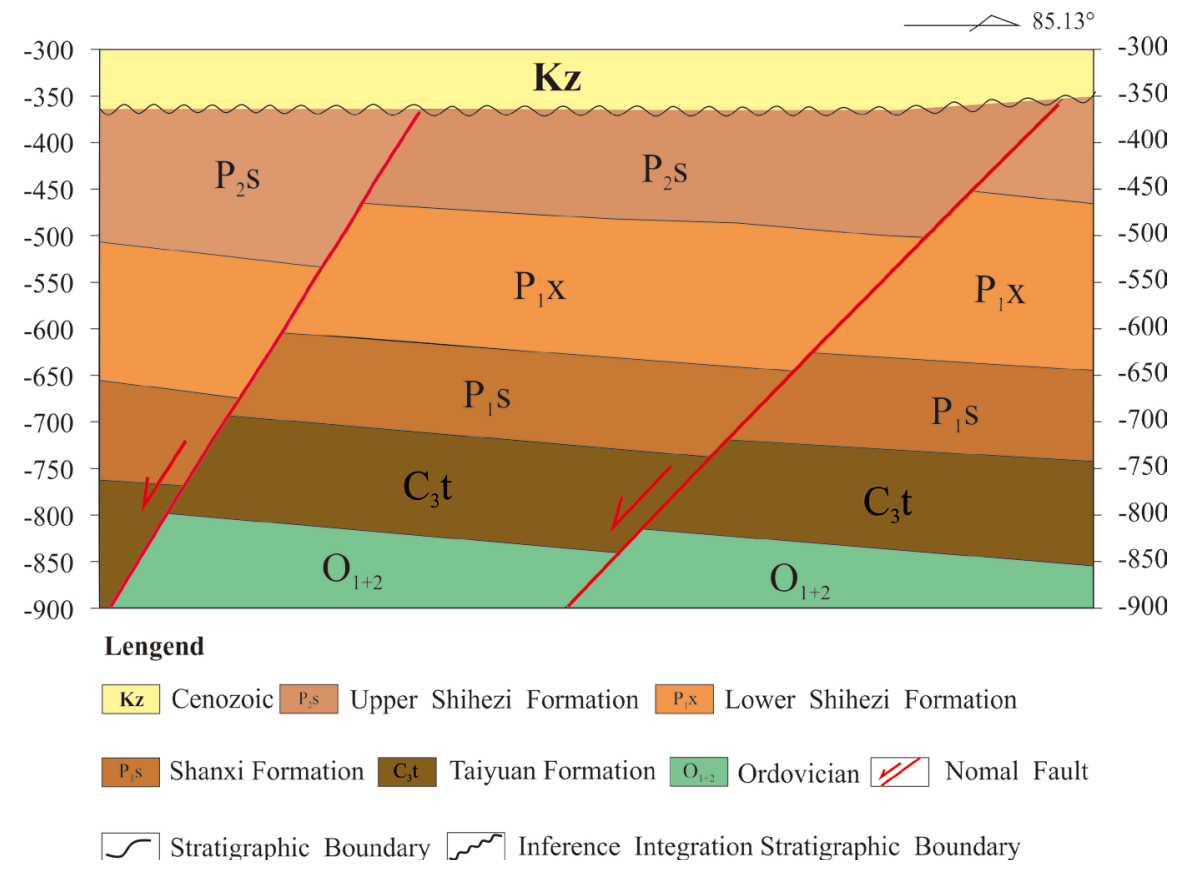

Figure 2. Half graben structure.

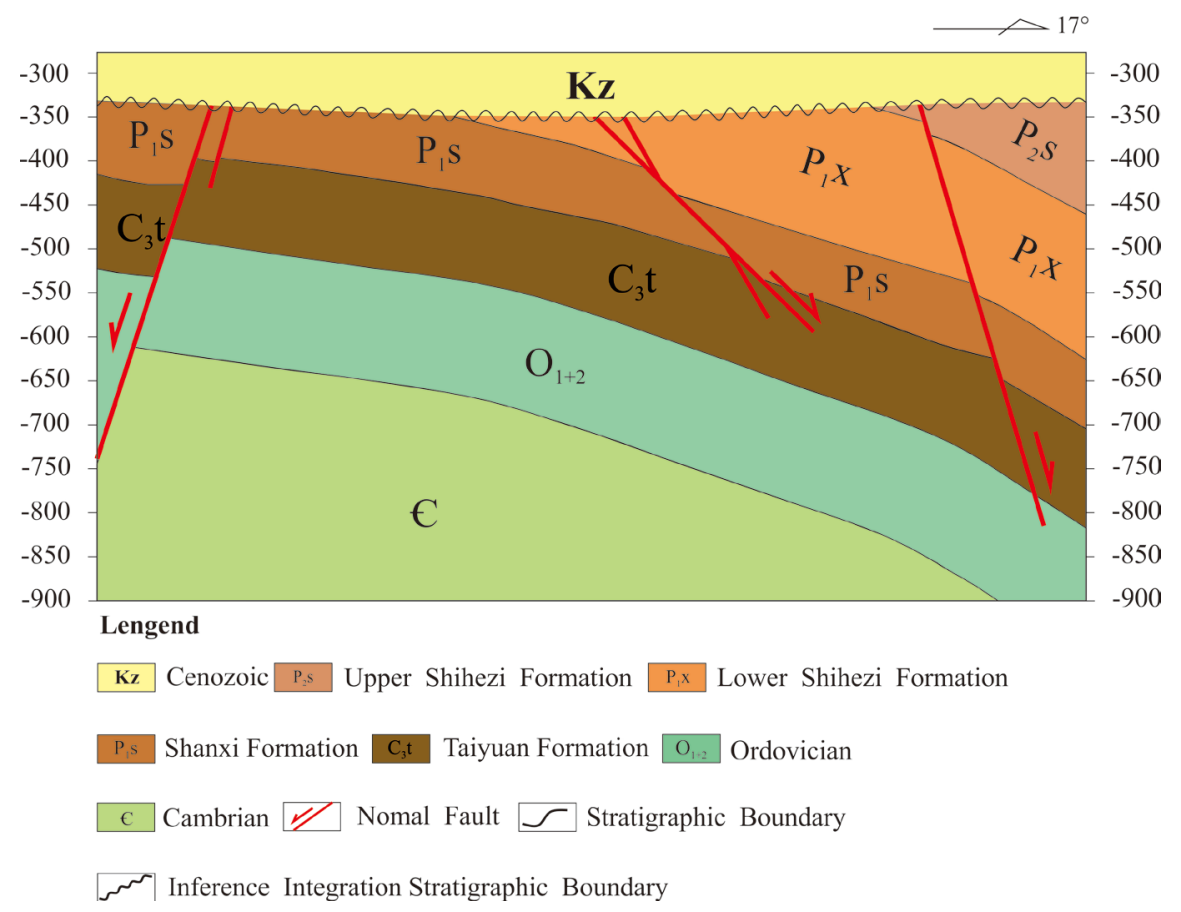

Figure 3. Horst structure.

\section{5) Imbricate Thrust Structure}

Imbricated thrust faults are the most common combination of thrust faults. For example, Large-scale thrust-imbricated structure combine with Fuli fault, Shanwangji fault and Fufeng fault, small imbricate structure is also common, such as imbricated thrust structures composed of EF41, F1, EF11, F66 and EF12 in Pan two mining area (Figure 5). 


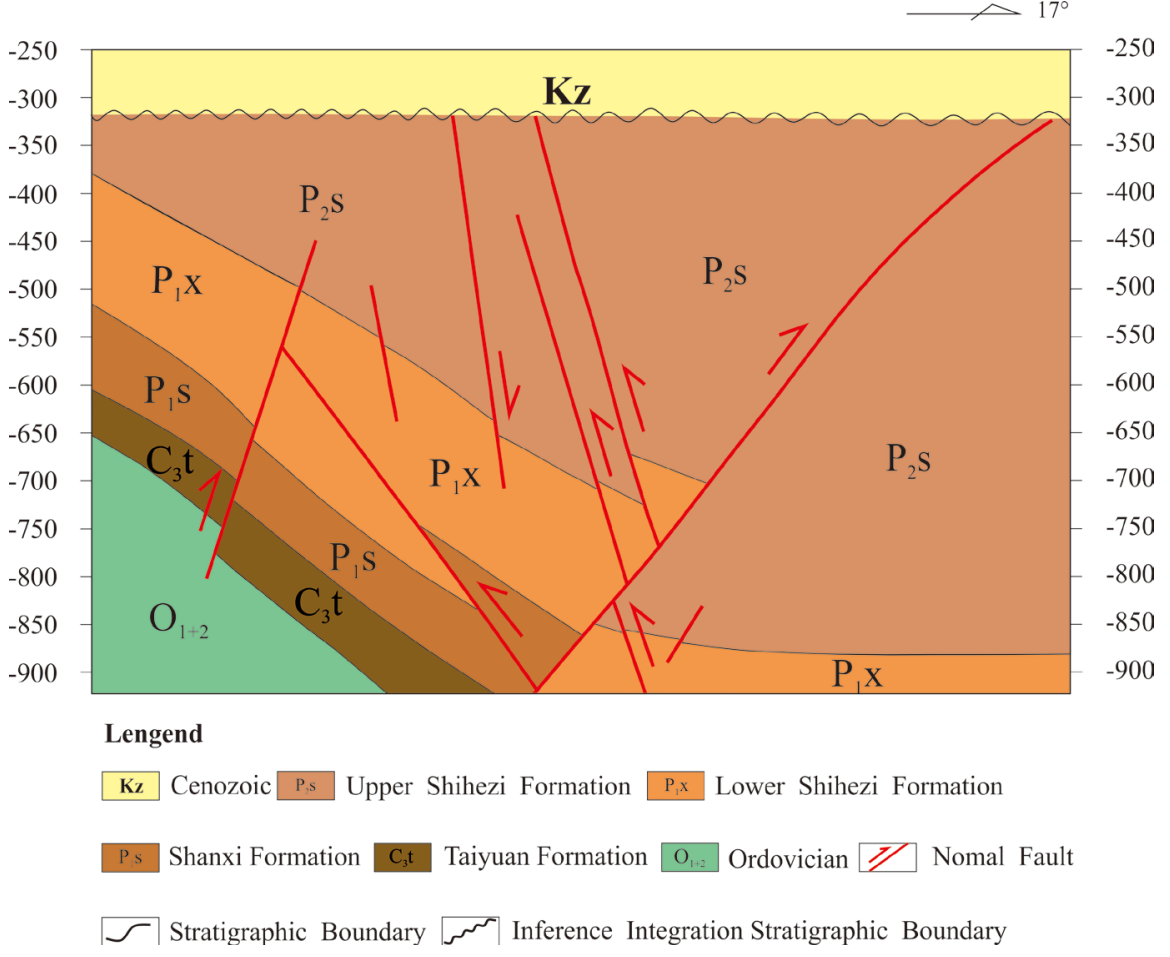

Figure 4. Reserve thrust structure.

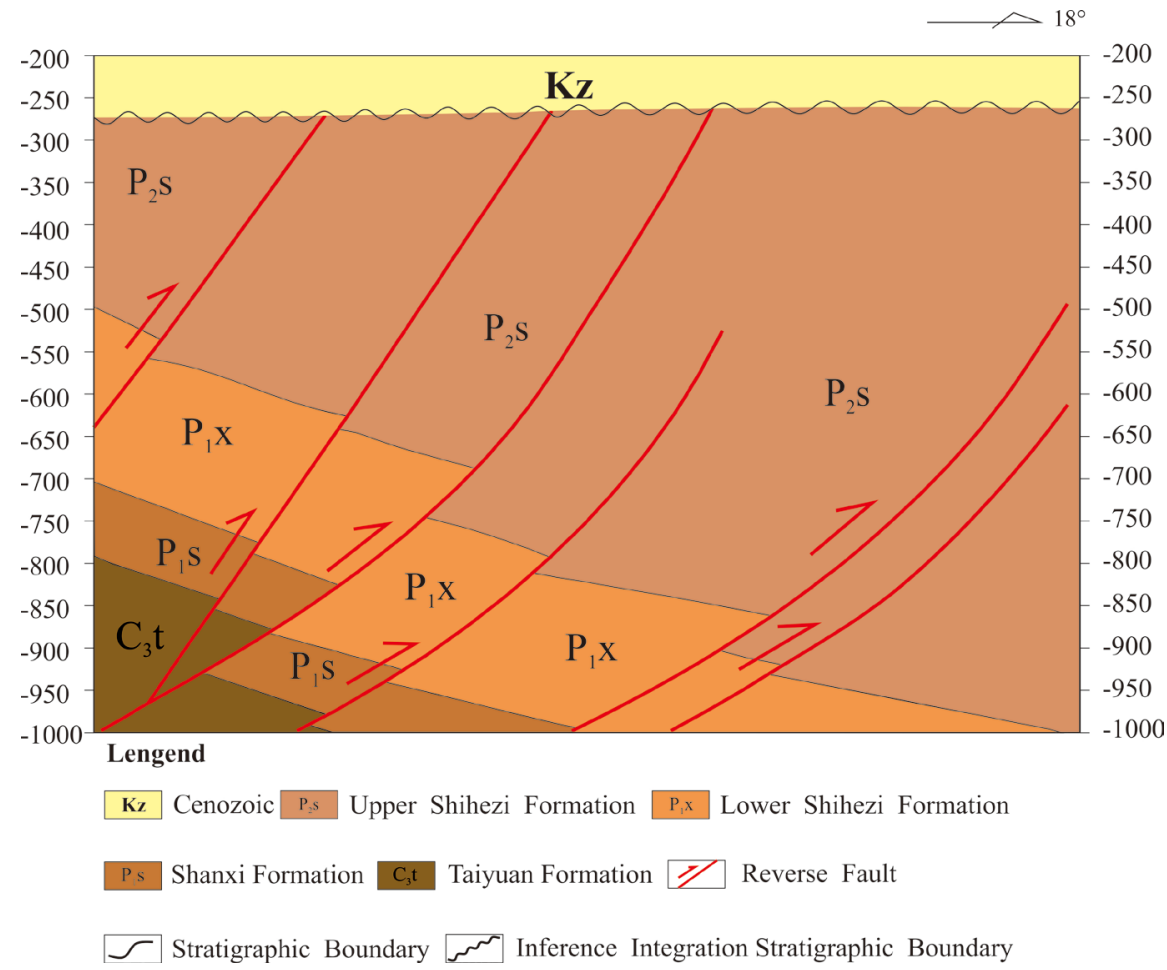

Figure 5. Imbricate thrust structure.

\section{6) Translational Faults and Striking Sliding Structures}

Translational faults usually do not exist independently, especially strike-slip faults, because secondary faults often develop and secondary folds are easy to 
form. In Panxie mining area, there are many displacement faults of different sizes, and now V, large NW-trending left-trending strike-slip faults, such as Fuyang fault, Kouziji fault, and Chenqiao fault, are all early strike-slip faults. Also, various research results confirm that there have been large-scale strike-slip phenomena on the Tan-Lu fault zone in the eastern part of the North China plate, given priority to left-lateral translation, and the formation of translation faults in the study area is closely related to it.

\section{7) Other Structural Styles}

The main faults in this area are high-angle faults, so the sections of common main faults and their secondary faults assemblage are Y-type, anti-Y-type and V-type assemblages. On this basis, the more complex composite faults assemblages are flower-like, and most of these assemblages are located in the upper part of the fault basin.

\subsection{Data Collection and Collation}

According to the "Detailed Rules for Coal Mine Water Prevention", the unit water inflow value (hereinafter referred to as $q$ ) as the foundation, the aquifer water-rich grade is divided. By comparing the unit water inflow data in different structural style sections (Table 2), the water control law of different types of structural styles were explored for the Taiyuan Formation. In the process of data statistics, because the nature of reverse thrust was the same as thrust fault, it is classified into one category for the convenience of induction and statistics. Meanwhile, there are very few thrust nappe structures in the Panxie mining area, which are not counted.

\subsection{Results of Water Abundance}

It can be seen from Figure 6 that the $q$ value of graben pattern ranges from 2.92 $\times 10^{-3}$ to $0.306 \mathrm{~L} \cdot(\mathrm{s} \cdot \mathrm{m})^{-1}$ with an average value of $0.107 \mathrm{~L} \cdot(\mathrm{s} \cdot \mathrm{m})^{-1}$, the $q$ value of

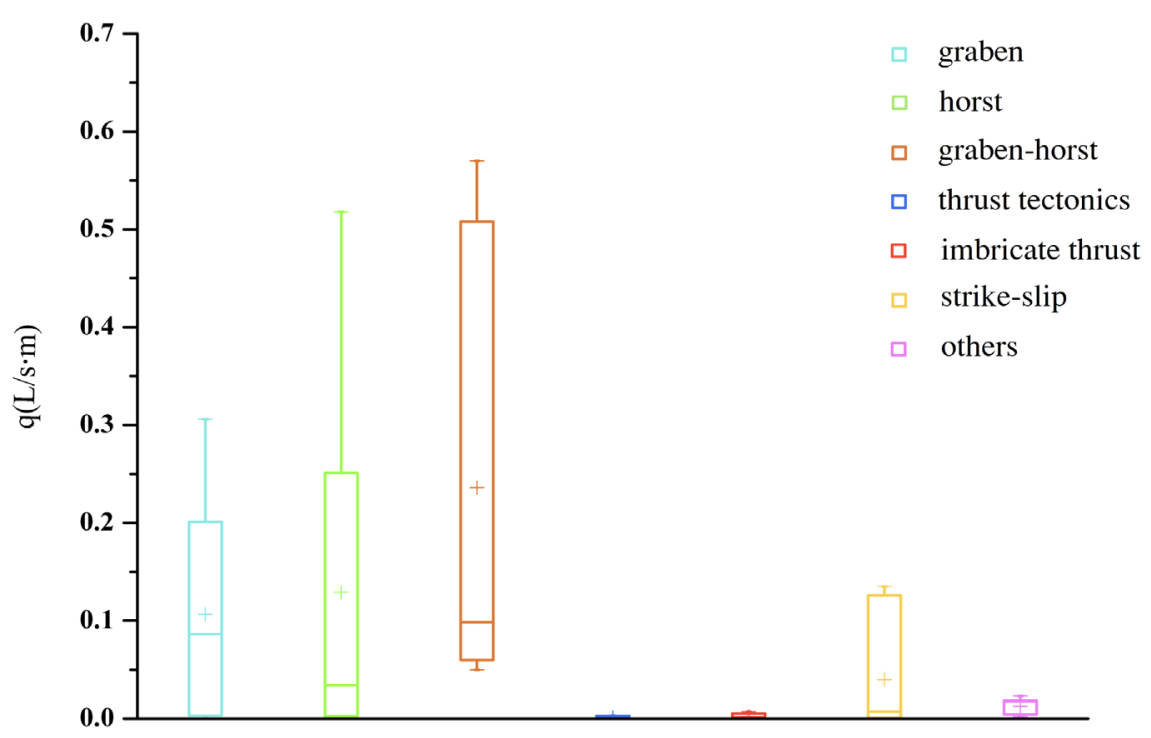

Figure 6. $q$-structural styles box plot. 
Horst pattern ranges from $1.41 \times 10^{-3}$ to $0.518 \mathrm{~L} \cdot(\mathrm{s} \cdot \mathrm{m})^{-1}$ with an average value of $0.129 \mathrm{~L} \cdot(\mathrm{s} \cdot \mathrm{m})^{-1}$, and the $q$ value of graben-barrier combination pattern ranges from 0.05 to $0.57 \mathrm{~L} \cdot(\mathrm{s} \cdot \mathrm{m})^{-1}$, with an average value of $0.41 \times 10^{-3}$ to $0.518 \mathrm{~L} \cdot(\mathrm{s} \cdot \mathrm{m})^{-1}$. The value is $0.236 \mathrm{~L} \cdot(\mathrm{s} \cdot \mathrm{m})^{-1}$. The $q$ value of the positive (reverse) thrust structure style is between $5.5 \times 10^{-6}$ and $3.23 \times 10^{-3} \mathrm{~L} \cdot(\mathrm{s} \cdot \mathrm{m})^{-1}$. The average value is $1.28 \times$ $10^{-3} \mathrm{~L} \cdot(\mathrm{s} \cdot \mathrm{m})^{-1}$. The $q$ value of the imbricated thrust structure is between $1.5 \times$ $10^{-4}$ and $7 \times 10^{-3} \mathrm{~L} \cdot(\mathrm{s} \cdot \mathrm{m})^{-1}$. The average value is $2.39 \times 10^{-3} \mathrm{~L} \cdot(\mathrm{s} \cdot \mathrm{m})^{-1}$. The average $q$ value of strike-slip fault is $0.04 \mathrm{~L} \cdot(\mathrm{s} \cdot \mathrm{m})^{-1}$, and the $q$ values of other styles are $0.0233-0.002 \mathrm{~L} \cdot(\mathrm{s} \cdot \mathrm{m})^{-1}$. The average value is $0.013 \mathrm{~L} \cdot(\mathrm{s} \cdot \mathrm{m})^{-1}$. There is a relationship among the seven groups of water-rich, from strong to weak, graben-horst combination structure, horst, graben, strike-slip structure, others, imbrication thrust structure, forward thrust structure, and the difference is obvious.

\section{Discussions}

Overall, when the $q$ value is greater than $0.1 \mathrm{~L} \cdot(\mathrm{s} \cdot \mathrm{m})^{-1}$, the aquifer belongs to medium water abundance, while the $q$ value smaller than $0.1 \mathrm{~L} \cdot(\mathrm{s} \cdot \mathrm{m})^{-1}$, it belongs to weak. Based on the data analysis results, the controlling effect of fracture structure style on water-rich of Taiyuan limestone karst aquifer is discussed.

1) Box-type map shows that the maximum, mean and threshold of $q$ value of Taiyuan aquifer in graben-horst combination structural style are the largest among the seven fault structural styles, indicating that deep karst is rich in water. The reason may be that the structure of graben-horst combination is more complex, and the horst-graben structure alternate and intergrowth, the depth of stratum in horst section is shallow but water supply of the graben section acts as the discharge outlet of water flow, which causes the hydrodynamic conditions of the whole tectonic area abundant, the water storage space is large and the water source is abundant. To summarize, the aquifer of Taiyuan formation is rich in water.

2) The water abundance in the horst structure area is richer than the limestone aquifer controlled by graben structure. The reason is that the horst-controlled stratum uplifts above the erosion base level receives the recharge of atmospheric precipitation and participates in the circulation of the atmosphere and hydrosphere, which makes the karst development more complete and the storage space of groundwater larger.

3) The amount of water inflow in the positive (reverse) thrust structure and imbricate thrust structure is very small, and there is no leakage phenomenon in the borehole. From the structural stress aspect, it is explained that the positive (reverse) thrust structure and imbricate thrust structure are all squeezed fracture structures, and the fault surface is tightly closed by the compression stress, which blocks the flow of water. And there is little difference in water abundance between them.

4) Although the strike-slip faults are both compressive because of their large scale, secondary faults and complex structures, which make the water conductiv- 
ity better than other compressive faults, but they are still weak water abundance.

5) The "flower pattern", "Y" type, anti "Y" type and "V" type of other composite structural styles are mostly extruded fault structures, and the profile forms are generally "bowl-shaped" from shallow to deep, and rarely reach the limestone group in depth. Hence it does not have the function of conducting other aquifers and is weak in water-rich.

\section{Conclusions}

1) The results of $q$-structural style box plot analysis show that there are significant differences in water-enrichment among different types of fault structural styles, i.e. fault structural styles have a certain water-controlling effect on the Taiyuan aquifer in the study area, and the order of seven structural styles with water abundance from strong to weak is: graben-horst combination structure, horst structure, graben structure, strike-slip fault structure, other structural styles, imbricated thrust, forward (reverse) thrust structure.

2) Through the borehole data and core image verification of the mining area, the analysis results of the $q$-structural style box plot coincide with the water-rich character of the Taiyuan limestone aquifer in the study area. The $q$-structural style box diagram can be used for the study of the water control law in the study area.

3) In view of the water-rich property of the limestone group aquifer in the data obtained by data analysis, the corresponding group A coal mining prevention and control works should be worked out, and the section with the development of the graben barrier structure, the horst and the graben should be investigated more, and the waterproof pillar should be reserved for the prevention and prediction work. However, for the area with positive (reverse) thrust structure, the imbricate thrust structure, strike-slip fault or other structural styles, because water abundance in the above zone is relatively weak, even water blocking, the possibility of karst water disaster is very small, the tunneling volume could be increased appropriately.

\section{Conflicts of Interest}

The authors declare no conflicts of interest regarding the publication of this paper.

\section{References}

[1] Liu, X.Y., Li, W.M., Liu, Y.J., et al. (2019) Archean Tectonic Pattern and Its Numerical Simulation in Anshan Area, Eastern Liaoning Province. Acta Petrologica Sinica, 35, 1071-1084.

[2] Yan, D.P., Qiu, L., Chen, F., et al. (2018) Structural Style and Kinematics of the Mesozoic Xuefengshan Intraplate Orogenic Belt. Earth Science Frontiers, 25, 1-13.

[3] Cowan, D.S. (1985) Structural Styles in Mesozoic and Cenozoic Melanges in the Western Cordillera of North America. Geological Society of America Bulletin, 96, 451-462. https://doi.org/10.1130/0016-7606(1985)96<451:SSIMAC>2.0.CO;2 
[4] Jiang, D.W., Zhang, S.M., Li, W., et al. (2018) Foreland Deformation Pattern of the Southern Longmen Shan in Late Quaternary. Chinese Journal of Geophysics, 61, 1949-1969.

[5] He, Z.L., Xu, H.J. and Duan, T.J. (2005) A Preliminary Analysis on Compound Structural Styles in the Tarim Polycyclic Basin. Chinese Journal of Geology, 40, 153-166.

[6] He, D.F., Shao, D.B., Kai, B.Z., et al. (2019) Structural Style and Trap Distribution in Majiatan Area on the Western Margin of Ordos Basin. Acta Geoscientica Sinica, 40, 219-235.

[7] Song, Y., Zhao, M.J., Fang, S.H., et al. (2013) Differential Hydrocarbon Accumulation Controlled by Structural Styles along the Southern and Northern Tianshan Thrust Belt. Acta Geoscientica Sinica, 87, 1109-1119. https://doi.org/10.1111/1755-6724.12113

[8] Wang, G.P., Cheng, S. and Hao, H.N. (2018) Recent Progress on the Structural Styles of Journal Foil Gas Bearings. IOP Conference Series Materials Science and Engineering, 439, Article ID: 042016. https://doi.org/10.1088/1757-899X/439/4/042016

[9] Zheng, F.Y., Shi, B.Q., Li, Z.H., et al. (2018) Paleogene Structure Styles and Their Controls on the Hydrocarbon Accumulation in the Termit Basin. Earth Science Frontiers, 25, 72-82.

[10] Fang, W.X., Wang, L., Guo, Y.Q., et al. (2018) Tectonic Patterns in the Sarekebayi Apart-Pull Basin and Their Ore-Controlling Regularities for the SarekeGlutenite-Type Copper Deposit in Xinjiang, China. Earth Science Frontiers, 25, 240-259.

[11] Wang, T., Xia, Y.C., Wei, B., et al. (2017) Structural Styles and Their Control Effect on Jurassic Coalfield in Xinjiang. Journal of China Coal Society, 42, 436-443.

[12] Blanc, J.P., Allen, M.B., Inger, S., et al. (2003) Structural Styles in the Zagros Simple Folded Zone, Iran. Journal of the Geological Society, 160, 401-412. https://doi.org/10.1144/0016-764902-110

[13] Liu, H.F., Liang, H.S., Cai, L.G., et al. (1994) Structural Styles of the Longmenshan Thrust Belt and Evolution of the Foreland Basin in Western Sichuan Province, China. Acta Geologica Sinica (English Edition), 7, 351-372. https://doi.org/10.1111/j.1755-6724.1994.mp7004001.x

[14] Zhang, L.Z. (2013) Mechanism of Water Inrush for Coal Mine Deep Exploitation. Chang'an University, Xi'an.

[15] Zhao, C.X. (2015) The Water Inrush Mechanism and Governmental Mode of Deep Karst in Huaibei Mine. China University of Mining and Technology, Xuzhou.

[16] Shi, Z.Y. (2015) Application of Horizontal Well Drilling Method in High-Pressure Karst Water Hazards Region Advanced Management of Coal Floor. Safety in Coal Mines, 46, 67-70+75. 